Bangladesh J. Zool. 48(2): 347-356, 2020

ISSN: 0304-9027

eISSN: $2408-8455$

\title{
URINARY TRACT INFECTION AMONG THE OUTPATIENTS OF A DIAGNOSTIC CENTER IN DHAKA, BANGLADESH
}

\author{
Sonia Rustom, Rimi Farhana Zaman, Priyanka Barua and Hamida Khanum* \\ Department of Zoology, University of Dhaka, Dhaka, Dhaka-1000, Bangladesh
}

\begin{abstract}
Urinary tract infection (UTI) is one of the common bacterial infections occurring in the community and in hospitals of Bangladesh. A total of 300 urine samples were tested for UTI among which 100 were from children (age 1-15 years), 100 from adult female (16-75 years) and 100 from adult male (16-75 years). Out of 300,126 samples were found positive for UTI $(42 \%)$. The highest prevalence was observed among adult female (64\%) followed by male and children (31\% each). According to age groups, the highest prevalence was observed in female aged $16-35$ years $(70.73 \%)$ followed by female of $36-55$ years $(62.5 \%)$ and 56-75 years $(52.63 \%)$. The highest prevalence for children was observed in age group 11-15 years (33.33\%) and for adult male, it was $16-35$ years $(34.88 \%)$. The highest prevalence for adult female and male was observed in summer $166.67 \%$ and 38\% respectively). The current study confirmed that Bangladeshi women and children are more vulnerable to UTI than Bangladeshi men. Regardless of age, women were more prone to UTI and the prevalence was highest in summer.
\end{abstract}

Key words: Urinary tract infection (UTI), Season, Adult and children.

\section{INTRODUCTION}

Urinary tract infection (UTI) is one of the common infectious disease in human affecting 150 million people every year (Stamm and Norrby 2001). This statement contrasts to present finding. This must be discussed in discussion. During their adult lifespan, 50\% of women suffer from at least once with UTI whereas others may suffer with high risk of morbidity from the effects of pyelonephritis (an infection of the kidney substance). Alarmingly, about $25 \%$ of those who have had one infection will have at least one further infection and sometimes, multiple recurrences (Stapleton 1999).

Infection of the urinary tract is an extremely common clinical problem (Foxman 2010). In general, the presence of microorganisms in the urinary tract is termed as UTI (Flores-Mireles et al. 2015). Even today, UTI is one of the most important causes of morbidity and mortality in developing countries like

*Author for correspondence: <hamida_khanum@yahoo.com>

(02020 Zoological Society of Bangladesh DOI: http://doi.org/10.3329/bjz.v48i2.52374 
Bangladesh. This may be attributed to the lack of proper research, flawed diagnostic procedures, mishandling of chemotherapeutic agents etc. The alarming phenomenon of UTI is that it does not restrict itself to the urinary tract; rather it can spread. UTIs can cause inflammation of the affected tissues of the urethra (urethritis) and urinary bladder.

In case of lower tract involvement (Urethritis and cystitis), manifestations include burning pain on urination with foul smelling or dark urine; with lower abdominal discomfort (Flores-Mireles et al. 2015). The most significant danger from lower urinary tract infections is that they can affect the kidneys and develop into subsequent bladder infections (Najar et al. 2009). Bacteria carried by blood stream can also infect the kidneys and the infections become difficult to eradicate, leading to chronic infection. Cystitis is an inflammation of the urinary bladder and is very common, especially among females. In case of upper urinary tract involvement (pyelonephritis), in $25 \%$ of untreated cases, cystitis may progress to pyelonephritis, an inflammation of one or both kidneys. In recurrent or persistent UTI, patient with lower urinary tract involvement tend to have repeated bouts of transient symptomatic or asymptomatic infection. UTI risk factors may also comprise urinary incontinence (Raz et al. 2000). Better recognition of risk factors, prompt diagnosis and early intervention are sufficient enough to maintain normal renal function and healthy lifestyle (Edler 2012).

The course of UTI infection is dependent on the ability of the pathogens to overcome the complex defense system of human body (Najar et al. 2009). The most common aerobic organisms causing UTI are Escherichia coli, Klebsiella spp., Enterobacter sp., Pseudomonas spp., and Proteus spp. Other bacteria e.g. Staphylococcus saprophyticus may occasionally appear in spontaneous urinary infection (Flores-Mireles et al. 2015). More than 95\% of urinary tract infections are caused by a single bacterial species and $E$. coli is the most frequent infecting organism in acute infection (Ronald 2002). It has been observed that only a small number of serologically distinct strains are responsible for the infections caused by E. coli.

Previous investigations in Bangladeshi people showed that women were the usual victims of the urinary pathogens. For example, a study conducted in Bangladesh in a tertiary level hospital showed the presence of pus in the urine (pyuria) in nearly all patients (92\%) (Islam et al. 2010). Nahar et al. (Nahar 2006) reported that $64.1 \%$ of the $E$. coli infection occurred in women and this was linked to UTI. Currently, there is scarcity of proper clinical and epidemiological studies conducted among Bangladeshi patients.

The aim of the study was to determine the comparative prevalence of UTI in adult female, male and children of Bangladesh. The present study provided a 
detailed insight on the occurrence of UTIs among the outpatients from a diagnostic center in Bangladesh. The current study further tried to confirm whether women and children are the most at risk groups for UTI and to identify the age and season in which people are more prone to get UTIs. Further studies should focus on identifying the different organisms related to UTIs.

\section{MATERIAL AND METHODS}

A total of 300 urine samples were collected from the outpatients of a diagnostic center from Bangladesh for one year. The study population was adult female and male (age 16-75 years) and children (age 1-15 years). They were further divided into following age groups: children (1-5, 6-10, 11-15 years) and adult male, female (16-35, 36-55, 56-75 years). The samples were collected during summer (May to July) and winter (October to December). For sample collection, clean catch, midstream urine samples (MSU) were collected in sterile, wide mouthed, universal containers from the patients clinically suspected to have UTI.

The specimens were immediately transported to the laboratory and processed within two hours of the collection. Quantitative un-spun wet mount microscopic examination was done for the well mixed un-centrifuged urine sample. $50 \mu 1$ of urine sample was placed on clean grease free glass slide and covered with $20 \mathrm{~mm} \times 20 \mathrm{~mm}$ coverslip and was examined under high power field of microscope model, brand, nature should be mentioned for the presence of pus cells. The cut off for the significant finding was 1 pus cell / 7 high power fields (hpfs) (Colleen 2003).

\section{RESULTS AND DISCUSSION}

The present study was done to determine the prevalence of urinary tract infection among the outpatients of a hospital in Bangladesh in order to identify the UTIs among Bangladeshi children and adult patients. This study provided the prevalence of UTIs according to age, gender and season in Bangladeshi patients.

Among 300 tested samples, 100 were from children (age 1-15 years), 100 were from adult female (age 16-75 years) and 100 from adult male (aged 16-75 years). Out of 300 urine samples, 126 were found positive for UTI (42\%). The highest prevalence was observed among adult female (64\%) followed by male and children (31\% each) (Table-1). According to a previous study (Singh 2016), females are more susceptible to UTI as compared to males due to the short length of urethra, absence of prostatic secretion, pregnancy and easy 
contamination of the tract with fecal flora. In the current study, the highest prevalence of UTI was observed among adult female (64\%) similar to previous findings (Nahar 2006).

Previous studies reported that the prevalence rates of UTI varied by age, gender, race and circumcision status (Shaikh et al. 2008). When the study population were divided into different age groups, the highest prevalence was observed in female aged 16 to 35 years $(70.73 \%)$ followed by female of 36-55 years $(62.5 \%)$ and $56-75$ years $(52.63 \%)$. The highest prevalence for children was observed for age group 11-15 years (33.33\%) and for adult male, it was 16-35 years (34.88\%) (Table-2). The highest prevalence among all age groups were observed among the 16-35 years of women (70.73\%) which is consistent with previous studies. Sexual activities of women have been considered as an important risk factors for UTI infections and recurrences (Kelsey et al. 1979) which may relate to the fact that sexually active adult women (16-35 years of age) had higher prevalence than comparatively older female of 36-55 years of age $(62.5 \%)$ and $56-75$ years of age $(52.63 \%)$.

In the present study, among all children, those aged 11-15 years old showed the highest prevalence of UTI (33.33\%) followed by 6-10 years old $(31.11 \%)$. Urinary tract is a common site of bacterial infection in infancy and childhood with potentially important implications (Nazme et al. 2017). UTI have been considered as an important risk factor for the development of renal insufficiency and end stage renal disease in children. Recognition of UTI in children should be made as early as possible to prevent from high morbidity and long term complications like renal scarring, hypertension, and chronic renal failure (Islam et al. 2010).

In the present study, among male patients, those aged 16-35 years old was the most UTI prevalent group (34.88\%) followed by $36-55$ years $(33.33 \%)$ but no infection was seen among the 56-75 age group (0\%). The high incidence observed in young male was probably due to ignorance about the cause of the disease and failure to maintain proper lifestyle to prevent UTI. However, the high incidence in middle to old age males may be due to prostate disease in males which are responsible for the increase in the incidence of UTI above 45 years. Similar observation was reported by several previous studies (Prakash and Saxena 2013; Sood and Gupta 2012). Pardeshi (2018) found the overall prevalence of UTI was $33.54 \%$ of which $66.78 \%$ were females and $33.22 \%$ were males. High prevalence was observed in females as compared to males (2:1) similar to the current finding. In his study, the overall prevalence was high in old aged ( $>45$ years) patients; in women, high prevalence was seen among 
middle-aged (31-45 years) patients and in men, high prevalence was seen among old age ( $>45$ years) patients; contrary to our study.

Table 1: Prevalence of UTI among the study population

\begin{tabular}{lccc}
\hline \multicolumn{1}{c}{ Groups } & $\begin{array}{c}\text { Total tested } \\
\text { patients }\end{array}$ & $\begin{array}{c}\text { Number of } \\
\text { positive cases (n) }\end{array}$ & $\begin{array}{c}\text { Prevalence } \\
\text { (\%) }\end{array}$ \\
\hline Children & 100 & 31 & 31 \\
Adult female & 100 & 64 & 64 \\
Adult male & 100 & 31 & 31 \\
Total & 300 & 126 & 42 \\
\hline
\end{tabular}

Table 2: Prevalence of UTI according to different age groups

\begin{tabular}{lccc}
\hline $\begin{array}{c}\text { Age group } \\
\text { (Years) }\end{array}$ & $\begin{array}{c}\text { Total } \\
\text { patients }\end{array}$ & $\begin{array}{c}\text { Number of } \\
\text { positive cases (n) }\end{array}$ & $\begin{array}{c}\text { Prevalence } \\
\text { (\%) }\end{array}$ \\
\hline Children & 10 & 2 & 20 \\
1-5 & 45 & 14 & 31.11 \\
6-10 & 45 & 15 & 33.33 \\
11-15 & 100 & 31 & 31 \\
Total & & & \\
Female & 41 & 29 & 70.73 \\
16-35 & 40 & 25 & 62.5 \\
36-55 & 19 & 10 & 52.63 \\
56-75 & 100 & 64 & 64 \\
Total & & & \\
Male & 43 & 15 & 34.88 \\
16-35 & 48 & 16 & 33.33 \\
36-55 & 9 & 0 & 0 \\
56-75 & 100 & 31 & 31 \\
Total & & & \\
\hline
\end{tabular}

Table 3: Prevalence of UTI according to different seasons

\begin{tabular}{|c|c|c|c|c|c|c|}
\hline \multicolumn{2}{|c|}{ children } & \multirow{2}{*}{$\begin{array}{c}\text { Adult } \\
\text { Prevalence } \\
\%\end{array}$} & \multirow{2}{*}{$\begin{array}{c}\text { male } \\
\text { Total no.l } \\
\text { positive cases }\end{array}$} & \multirow[b]{2}{*}{$\begin{array}{c}\text { Prevalence } \\
\%\end{array}$} & \multicolumn{2}{|c|}{ Adult female } \\
\hline Season & $\begin{array}{c}\text { Total no.l } \\
\text { positive cases }\end{array}$ & & & & $\begin{array}{c}\text { Total no.l } \\
\text { positive cases }\end{array}$ & $\begin{array}{c}\text { Prevalenc } \\
\text { e } \%\end{array}$ \\
\hline Summer & $50 / 21$ & 42 & $60 / 40$ & 66.67 & $50 / 19$ & 38 \\
\hline Winter & $50 / 10$ & 20 & $40 / 24$ & 60 & $50 / 12$ & 24 \\
\hline $\begin{array}{l}\text { Total } \\
\text { average }\end{array}$ & 100 & 31 & 100 & 64 & 100 & 31 \\
\hline
\end{tabular}

A total of 50 urine samples from children were tested in summer and 50 in winter showed the highest prevalence in summer (42\%). Similarly, the highest prevalence for adult female and male was observed in summer $(66.67 \%$ and $38 \%$ respectively). However, female in winter also had higher prevalence rate $(60 \%)$ than men and children (Table-3).

When divided in months, the highest prevalence for children were observed in June (46.67\%) followed by May (45\%) and July (33.33\%) (Fig. 1 ). Women in general had higher prevalence rate than the other two groups (adult male and children) in both the seasons but the prevalence was highest in the month of 
May (73.33\%) and July (70\%) (Fig. 2). In male, the highest prevalence was observed in June (49\%) followed by May (40\%) (Fig. 3). In the current study, the overall prevalence of UTI was more in summer season $(42 \%$ in children, $66.67 \%$ in female and $38 \%$ in male) than in winter season $(20 \%$ in

Table 4: Prevalence of UTI according to different age groups in summer

\begin{tabular}{lccc}
\hline $\begin{array}{l}\text { Age group } \\
\text { (Years) }\end{array}$ & $\begin{array}{c}\text { Total } \\
\text { patients }\end{array}$ & $\begin{array}{c}\text { Number of } \\
\text { positive cases (n) }\end{array}$ & Prevalence (\%) \\
\hline Children & 10 & 2 & 20 \\
1-5 & 20 & 11 & 55 \\
6-10 & 20 & 8 & 40 \\
11-15 & 21 & 42 \\
Total & 50 & & \\
Female & & 18 & 69.23 \\
16-35 & 26 & 15 & 65.21 \\
36-55 & 23 & 7 & 63.63 \\
56-75 & 11 & 40 & 66.67 \\
Total & 60 & & \\
Male & & 10 & 43.47 \\
16-35 & 23 & 9 & 40.91 \\
36-55 & 22 & 0 & 0 \\
56-75 & 5 & 19 & 38 \\
Total & 50 & & \\
\hline
\end{tabular}

Table 5: Prevalence of UTI according to different age groups in winter

\begin{tabular}{lccc}
\hline $\begin{array}{l}\text { Age group } \\
\text { Years) }\end{array}$ & $\begin{array}{c}\text { Total } \\
\text { patients }\end{array}$ & $\begin{array}{c}\text { Number of } \\
\text { positive cases (n) }\end{array}$ & $\begin{array}{c}\text { Prevalence } \\
\text { (\%) }\end{array}$ \\
\hline Children & & 0 & \\
$1-5$ & 0 & 3 & 0 \\
6-10 & 25 & 7 & 12 \\
11-15 & 25 & 10 & 28 \\
Total & 50 & & 20 \\
Female & & 11 & \\
16-35 & 15 & 10 & 73.33 \\
$36-55$ & 17 & 3 & 58.82 \\
$56-75$ & 8 & 24 & 37.5 \\
Total & 40 & & 60 \\
Male & & 5 & \\
16-35 & 20 & 7 & 25 \\
$36-55$ & 26 & 0 & 28 \\
$56-75$ & 4 & 12 & 0 \\
Total & 50 & & 24 \\
\hline
\end{tabular}

children, $60 \%$ in female and $24 \%$ in male). The probable cause could be the high temperature in summer season which causes more sweating than in winter, therefore urine production becomes less and concentrated which provides the opportunity for 
bacterial multiplication. On the contrary, during winter season, less sweating causes more diluted urine production which washes away any multiplying bacteria (Khanum 2013). Simmering et al. (2017) found that the seasonal intensity (summer peaks and winter troughs) increased over time among women while decreasing among men. In this study, both men and women, seasonality decreased with advancing age.

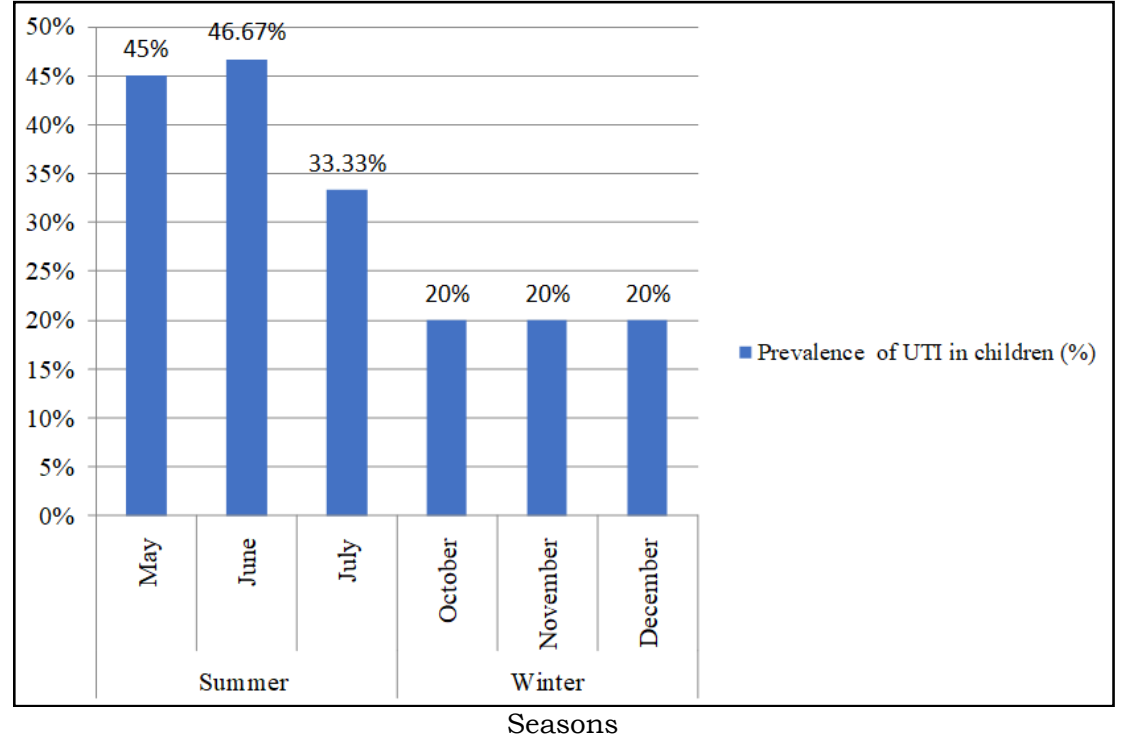

Fig. 1: Prevalence of UTI in children according to months

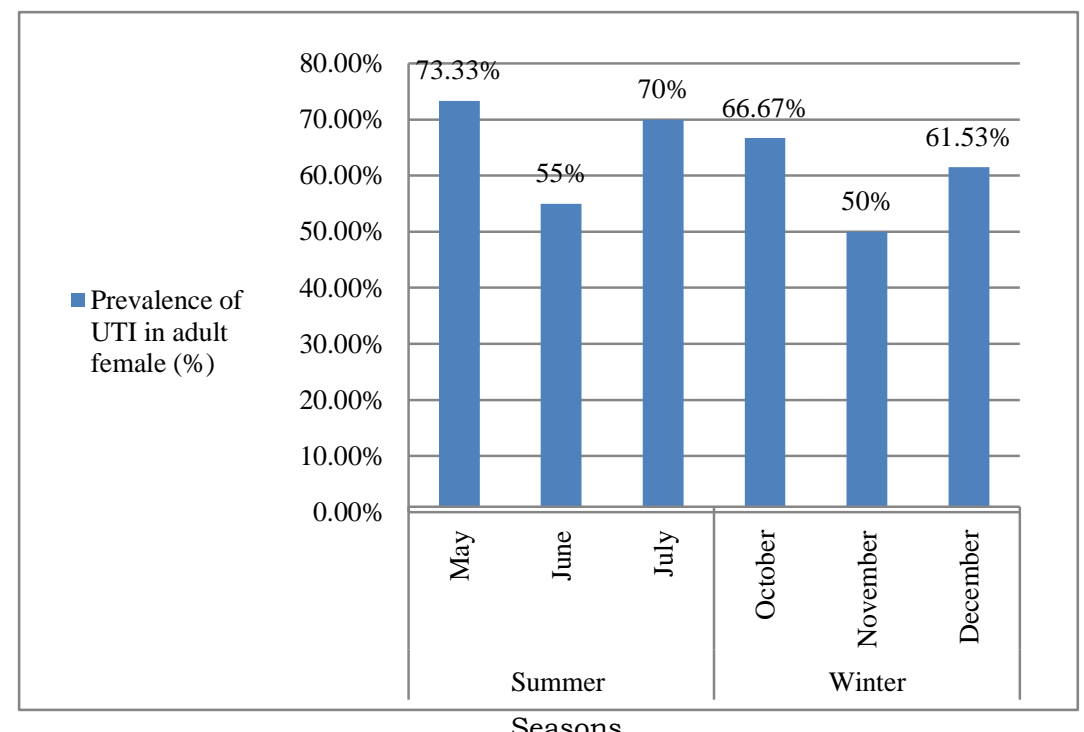

Fig. 2: Prevalence of UTI in adult female according to months 
Cross-tabulation showed, children aged 6-10 years had the highest prevalence during summer season (55.5\%) while both female and male aged 16-35 years

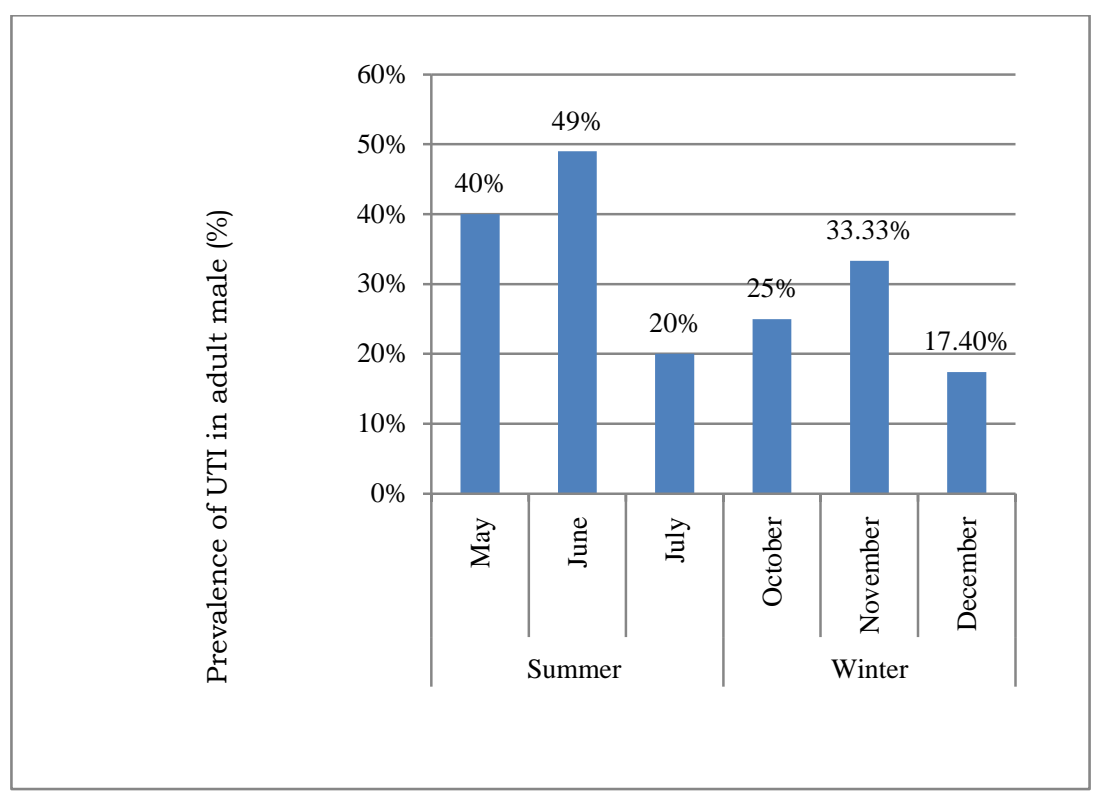

Seasons

Fig. 3: Prevalence of UTI in adult male according to months

had the highest prevalence rate (69.23\% and 43.47\%, respectively) (Table-4).

Similarly, the prevalence was highest in female aged 16-35 years in winter season $(73.33 \%)$ followed by women of $36-25$ years $(58.82 \%)$ and $56-75$ years $(37.5 \%)$. But in children, the highest rate was observed in age group 11-15 years $(28 \%)$ and in male for 36-55 years (28\%) during winter season (Table-5).

Within summer season, female of 16-35 of age were at risk of high UTIs (69.23\%) along with school going children of 6-10 years of age $(55 \%)$ which confirms the previous findings of women and children being the high-risk groups (Islam et al. 2010; Nahar 2006; Stapleton 1999). However, during winter, female of $16-35$ years showed the highest prevalence rate $(73.33 \%)$ confirming that women at 16-35 years of age are more prone to UTIs in both summer or winter season (Geerlings 2016; Johnson 1991).

The current study revealed an overview of the infection rate among various groups of patients according to age, gender and seasons. Although it lacked the proper tools to distinguish between various bacteria which causes UTI, this study provided further insight of the infection rate among immuno-compromised patients (e.g. women and children). 


\section{CONCLUSION}

UTI is a significant problem and still it is a cause of high morbidity and mortality in developing world. The current study confirmed the previous findings that women and children are the most vulnerable groups for UTI. The study also concluded that sexually active men and women (16-35 years) are more prone to the infection compared to older adults. Further systematic monitoring is essential at regular intervals to recognize the reliable information about the identification and resistance arrays of urinary pathogen.

\section{LITERATURE CITED}

COlleEn., D., P., FRASER, G., MARMiAn, P., MACKEY AND MCCARTNEY 2003. Practical Medical Microbiology. Churchill Livingstone Publishers, Longman Singapore.

EDLER, J.S. 2012. Nelson Textbook of Pediatrics. Saunders, Philadelphia.

FLORES-MIRELES, A.L., WALKER, J.N., CAPARON, M. and HULTGREN, S.J. 2015. Urinary tract infections: epidemiology, mechanisms of infection and treatment options. Nat Rev Microbiol. 13:269-284.

FOXMAN, B. 2010. The epidemiology of urinary tract infection. Nat Rev Urol. 7: 653-660.

GEERLINGS, S.E. 2016. Clinical Presentations and Epidemiology of Urinary Tract Infections. Microbiol Spectr. 4.

ISLAM, M., KHALEQUE, M., SIDDIKA, M. and HOSSAIN, M. 2010. Urinary tract infection in children in a tertiary level hospital in Bangladesh. Mymensingh Medical Journal: MMJ 19: 482-486.

JOHNSON, C.C. 1991. Definitions, classification, and clinical presentation of urinary tract infections. Med Clin North Am . 75:241-252.

KELSEY, M.C., MEAD, M.G., GRUNEBERG, R.N. and ORIEL, J.D. 1979. Relationship between sexual intercourse and urinary-tract infection in women attending a clinic for sexually transmitted diseases. J Med Microbiol. 12: 511-512.

KHANUM, H., FAHMIDA, M., SHAFIULLAH, ABU ZAR and MUZNEBIN, FARHANA. 2013. Prevalence and comparative likelihood of Urinary Tract Infection (UTI) among female outpatients in BSMMU. Bangladesh J. Zool. 40(2):231-239.

NAHAR, S.K., KHANUM, H., and ZAMAN, R.F., 2006. Occurrence of Escherichia coli infection among the children of Dhaka city. Bangladesh J. of Zool.. 34(2):181-186.

NAJAR, M.S., SALDANHA, C.L. and BANDAY, K.A. 2009. Approach to urinary tract infections. Indian J Nephrol. 19: 129-139.

NAZME, N.I., AL AMIN, A., JALIL, F., SULTANA, J. and FATEMA, N.N. 2017. Bacteriological profile of urinary tract infection in children of a Tertiary Care Hospital. Bangladesh Journal of Child Health.41: 77-83. 
PARDESHI, P. 2018. Prevalence of urinary tract infections and current scenario of antibiotic susceptibility pattern of bacteria causing UTI. Indian J. Microbiol. 5:334-338.

PRAKASH, D. and SAXENA, R.S. 2013. Distribution and antimicrobial susceptibility pattern of bacterial pathogens causing urinary tract infection in urban community of Meerut city, India. ISRN Microbiol, 629-749.

RAZ, R., GENNESIN, Y., WASSER, J., STOLER, Z., ROSENFELD, S., ROTTENSTERICH, E. and STAMM, W.E. 2000. Recurrent urinary tract infections in postmenopausal women. Clin Infect Dis. 30: 152-156.

RONALD, A. 2002. The etiology of urinary tract infection: traditional and emerging pathogens. Am $J$ Med.113 Suppl 1A, 14s-19s.

SHAIKH, N., MORONE, N.E., BOST, J.E. and FARRELL, M.H. 2008. Prevalence of urinary tract infection in childhood: a meta-analysis. Pediatr Infect Dis J. 27: 302-308.

SIMMERING, J.E., TANG, F., CAVANAUGH, J.E., POLGREEN, L.A. and POLGREEN, P.M. 2017. The Increase in Hospitalizations for Urinary Tract Infections and the Associated Costs in the United States, 1998-2011. Open Forum Infect Dis. 4: 281.

SINGH, R.K., AND BIJOYLAKSHMI, D. 2016. Prevalence of antibiotic sensitivity pattern of uropathogns in patients of different age-groups from western region of Nepal. Int. J. Med. Res. Health Sci. 5: 1-7.

SOOD, S. and GUPTA, R. 2012. Antibiotic resistance pattern of community acquired uropathogens at a tertiary care hospital in Jaipur, Rajasthan. Indian J Community Med. 37: 39-44.

STAMM, W.E. and NORRBY, S.R. 2001. Urinary tract infections: disease panorama and challenges. $J$ Infect Dis. 183: Suppl 1: 1-4.

STAPLETON, A. 1999. Prevention of recurrent urinary-tract infections in women. Lancet. 353: 7-8.

(Manuscript received on 14 February, 2020 revised on 20 August, 2020) 